\title{
Macular Pigment Optical Density in Young Adults of South Asian Origin
}

\author{
Olivia Howells, Frank Eperjesi, and Hannah Bartlett \\ Ophthalmic Research Group, School of Life and Health Sciences, Aston University, Birmingham, United Kingdom
}

Correspondence: Olivia Howells, Ophthalmic Research Group, School of Life and Health Sciences, Aston University, Birmingham, UK; o.howells@aston.ac.uk.

Submitted: September 13, 2012 Accepted: February 27, 2013

Citation: Howells O, Eperjesi F, Bartlett H. Macular pigment optical density in young adults of South Asian origin. Invest Ophthalmol Vis Sci. 2013;54:2711-2719. DOI:10.1167/ iovs.12-10957
PurPose. To assess the range of macular pigment optical density (MPOD) in a healthy group of young adults of South Asian origin; to investigate whether any dietary factors or personal characteristics were related to intersubject variations in MPOD; and to compare the mean MPOD of the South Asian group with the mean MPOD of a white group.

Methods. Heterochromatic flicker photometry was used to measure the macular pigment (MP) levels of 169 healthy volunteers, of which 117 were Asian and 52 were white. In addition, the Asian participants completed a questionnaire pertaining to the various physical, ocular, lifestyle, dietary, and environmental factors that may be associated with MPOD or AMD.

REsults. The mean MPOD of the Asian subjects was $0.43 \pm 0.14$. The male participants had a higher mean MPOD than the females $(0.47 \pm 0.13$ vs. $0.41 \pm 0.14, P<0.01)$. Possible associations also emerged between MPOD and form of refractive correction, and iris color. No MPOD associations were found for the other variables examined in the questionnaire. The mean MPOD of the white subject group was $0.33 \pm 0.13$, which was significantly lower than the Asian group $(P<0.0005)$.

Conclusions. This study adds to the currently limited information on MPOD in South Asians, and while a comparison between Asians and Whites was not the main focus here, highly significant differences between these two ethnicities were revealed. This provokes the possibility that South Asian individuals could have a lower risk for AMD, and it warrants further study.

Keywords: age-related macular degeneration, heterochromatic flicker photometry, macular pigment, macular pigment optical density
$\mathrm{E}^{\mathrm{v}}$ vidence suggests that ethnicity has a role to play in AMD, with Whites having the highest prevalence and Blacks the lowest. ${ }^{1-13}$ The AMD prevalence in East Asians (Chinese/ Japanese), Southeast Asians (Malays), Hispanics, and Latinos has mostly been found to be lower than in Whites, but higher than in Blacks. ${ }^{14-21}$ Studies on South Asians (Indians/Pakistanis/ Bangladeshis/Sri Lankans) have been rare, but reported prevalences in a North and South Indian population were comparable to Western countries. ${ }^{22-24}$ Cheung and colleagues determined the prevalence of AMD in Chinese, Malay, and Indian persons in Singapore ${ }^{25}$ and found it to be similar between the three groups. Based on pooled data from Kawasaki et al., ${ }^{26}$ they concurred with the previous reports that prevalence is similar to Whites.

Macular pigment (MP) is the collective name for three carotenoids, lutein (L), zeaxanthin (Z), and meso-zeaxanthin (MZ), which are found at high concentrations in the central macula, to the exclusion of other carotenoids. ${ }^{27}$ They are only available through dietary/supplement intake. ${ }^{28,29} \mathrm{MP}$ is a blue light filter; its absorption spectrum peaks around $460 \mathrm{~nm} \cdot{ }^{30-33}$ It is well placed in the retina to reduce the amount of blue light reaching the photoreceptors; the higher the MP optical density (MPOD), the greater the amount of blue light filtering. ${ }^{34,35}$ It is also proposed that MP protects against oxidative stress. ${ }^{36,37}$ Since blue light and oxidative stress have been implicated in the pathogenesis of AMD, ${ }^{38,39}$ a high level of MP could reduce the risk for AMD. ${ }^{40-43}$

The relationship between race and MPOD has been rarely examined, largely because the vast majority of participants in MPOD studies have been white. Wolf-Schnurrbusch et al. ${ }^{44}$ compared MPOD in a group of 51 African and 67 white nonHispanic subjects. The mean MPOD for the African subjects was significantly higher than for the white subjects $(P<$ $0.0001)$. Conversely, Iannaccone et al. ${ }^{45}$ compared MPOD in a group of 35 black and 148 white subjects, and found it to be significantly higher in the Whites than Blacks $(P<0.0005)$. Nolan et al. ${ }^{46}$ compared 18 nonwhite (Indian, "Asian," Hispanic, and black) and 41 white subjects; mean MPOD was significantly higher in the nonwhite group than the white group $(P<0.01)$. Studies that found no statistically significant MPOD ethnicity differences ${ }^{47,48}$ had low numbers of nonwhite subjects (7\%-8\% of total samples) compared with white subjects, so there may have been a lack of statistical power.

Outside of ethnic comparisons and white subject-dominated MP studies, there have been a few MP investigations with East Asian participants, ${ }^{49-52}$ and one with South Asian participants. ${ }^{53}$

The aims of the current study were firstly to assess MPOD in a healthy group of young adults of South Asian origin. Secondly, to investigate whether any dietary factors or personal characteristics were related to intersubject variations in MPOD. 
Thirdly, to compare, for the first time to our knowledge, the mean MPOD of a South Asian group with that of a white group. Hereafter, the term "South Asian" is shortened to "Asian," and is not intended to encompass any other Asian groups.

\section{MeTHODS}

\section{Subjects}

Subjects were recruited by email and word of mouth, and consisted mainly of optometry students and staff from Aston University. One hundred and twenty Asian subjects were examined. The majority (104) were British born, 14 were Canadian, and two were African. All were in good health, with an age range of 18 to 30 years (mean \pm SD: $21.3 \pm 2.6$ years). MP measurements were also collected on 53 white participants; 47 were British, two were Canadian, and the others Australian, German, Irish, and Polish. All were in good health, with an age range of 18 to 61 years (mean \pm SD: $27.6 \pm 9.3$ years). The white subjects were not age-matched to the Asian subjects.

All participants had a habitual visual acuity (VA) of 0.14 logMAR (Snellen $6 / 7.5^{-2}$ ) or better in the eye being tested (the right eye unless it was unsuitable through poor acuity). Exclusion criteria were: age younger than 18 years; VA worse than 0.2 logMAR (Snellen 6/9.5) in the eye being tested; and the presence of any ocular disease in the eye being tested (all subjects were required to have had an eye examination within the last year).

Aston University's ethics committee approved the study. All subjects signed an informed consent form, and all procedures adhered to the tenets of the Declaration of Helsinki.

\section{Lifestyle Questionnaire}

A questionnaire was created for the Asian participants to complete. Questions were focused on the physical, ocular, lifestyle, dietary, and environmental factors that may be associated with MPOD or AMD, for example, height and weight (for body mass index [BMI] calculation), iris color, smoking history, fruit/vegetable consumption, sunlight exposure, and family history of AMD. A copy of the questionnaire is provided as Supplementary Material.

\section{Macular Pigment Screener (MPS) 9000}

Measurements of MPOD were taken using the MPS 9000 (MPSTinsley Ophthalmic, Redhill, Surrey, UK), a portable device that employs the heterochromatic flicker photometry (HFP) technique, and which has been described in detail elsewhere. ${ }^{54}$ In brief, HFP determines MPOD by presenting a light stimulus of two alternating wavelengths (blue, maximal absorption by MP, and green/yellow, minimal absorption by MP) at the fovea and at a parafoveal or perifoveal area, with the aim of achieving a perception of no or minimal flicker. In traditional HFP the blue-green alternation frequency remains constant, while the radiance of the blue light is increased/ decreased until minimal flicker is reported. The procedure is carried out with the subject looking directly at the stimulus (central/foveal measure), and then away from the stimulus (peripheral measure, where MP is assumed to be negligible). The presence of MP in the fovea (with subsequent absorption of some of the blue light before it reaches the photoreceptors) means that a greater radiance of blue light is required here for minimal flicker than at the eccentric point. The log ratio of the two values gives a measure of MPOD. The MPS uses the same HFP principle, but instead of responding to minimal flicker, subjects respond to the appearance of flicker as the blue-green alternation frequency decreases automatically. ${ }^{54}$ Rather than the radiance of the blue wavelength light being adjusted by the subject until minimal flicker, the subject registers their first perception of flicker throughout a series of blue-green ratios. Over the course of the test their responses create two Vshaped curves that are visible on a computer screen. One curve represents central viewing of a $1^{\circ}$ circular stimulus, and the other peripheral viewing ( $8^{\circ}$ eccentricity). An internal algorithm calculates the MPOD using the difference between the central and peripheral minima (the larger the difference, the higher the MPOD), but this can also be calculated manually.

An explanation of how to perform the MPS test was read by the investigator from an instruction sheet. Subjects wore their habitual distance correction, if appropriate, and the eye not being measured was occluded. Each subject performed two central and peripheral tests (a short practice was completed before the first of each). Because the MPS generates a visible curve as subjects respond to flicker, it provides a way for the operator to assess whether the curve adheres to the expected V-shape, giving an indication as to the accuracy of the MPOD value produced. The results were, therefore, screened at the time of data collection, and if a poor curve was obtained, or if there was a considerable difference between equivalent minimum readings (central or peripheral), then a third central and/or peripheral test was completed. The averages of the central minima and peripheral minima were used to calculate MPOD. Any poor quality curves were not included in the MPOD calculation. This method has been shown to provide excellent repeatability in subjects of similar ages to this study. ${ }^{55}$ Total testing time was 10 to 20 minutes per subject.

The main focus of this study was to examine an Asian subject group, and the numbers recruited were in line with several other MPOD studies that each examined a host of variables and their possible associations with MPOD. ${ }^{44,56-58}$ In addition, power calculations, using G*Power (version 3.1; Heinrich-Heine University, Düsseldorf, Germany), indicated that for an estimated significant mean difference in MPOD of 0.1 (with group SDs of 0.14 ), a sample size of 64, with 32 subjects per group, was required for $80 \%$ power at the $5 \%$ alpha significance level.

\section{Statistics}

SPSS (version 18.0; IBM, Portsmouth, UK) was used for data analysis. Mean values were mainly compared using two-tailed independent-samples $t$-tests or its nonparametric equivalent (the Mann-Whitney $U$ test), as appropriate in terms of normality. Pearson's $r$ or Spearman's rho correlations were used to quantify associations between continuous variables. A $P$ value of less than 0.05 was considered statistically significant.

\section{Results}

\section{Lifestyle Questionnaire}

Data from three Asian subjects were removed from the analyses due to inability to complete the MPS test. Of the remaining 117 participants with successful MPOD measurements, 100 fully completed the lifestyle questionnaire, and one subject partially completed it. Only limited information was available for the 16 other subjects. See Table 1 for descriptive statistics of the Asian group.

The mean MPOD of 117 Asian subjects was $0.43 \pm 0.14$. Other mean MPOD values on which statistical analyses were conducted are summarized in Table 1 . Some variables were not analyzed because of the very low subject numbers in one or more of the groups involved. These included: Asian back- 
TABLE 1. A Summary of the Physical, Ocular, Lifestyle, Dietary, and Environmental Data Collected on the Asian group, Along With the Corresponding MPOD

\begin{tabular}{lcc}
\hline \multicolumn{1}{c}{ Variable } & Value & MPOD \\
\hline All, $n$ & 117 & $0.43 \pm 0.14$ \\
Age, $\mathrm{y}$ & $21.3 \pm 2.6$ & N/A \\
Sex, $n$ & & \\
Male & $44(38 \%)$ & $0.47 \pm 0.13$ \\
Female & $73(62 \%)$ & $0.41 \pm 0.14$ \\
BMI & & \\
All & $21.9 \pm 4.0(n=100)$ & N/A \\
Male & $23.8 \pm 4.6(n=38)$ & N/A \\
Female & $20.8 \pm 3.1(n=62)$ & N/A \\
South Asian origin, $n$ & & \\
Indian & $75(71 \%)$ & $0.44 \pm 0.15$ \\
Pakistani & $22(21 \%)$ & $0.42 \pm 0.12$ \\
Bangladeshi & $3(3 \%)$ & N/A \\
Sri Lankan & $4(4 \%)$ & N/A \\
Other & $2(2 \%)$ & N/A
\end{tabular}

Iris color, $n$

Dark brown

Brown

Light brown

Hazel

Green

Brown + light brown

+ hazel + green

Smoking status, $n$

Current

Former

Never

$$
\begin{gathered}
61(58 \%) \\
37(35 \%) \\
1(1 \%) \\
5(5 \%) \\
2(2 \%)
\end{gathered}
$$

$45(42 \%)$

$$
\begin{gathered}
0.46 \pm 0.15 \\
0.42 \pm 0.14 \\
\text { N/A } \\
\text { N/A } \\
\text { N/A }
\end{gathered}
$$

Dietary background, $n$

Meat eater

Part vegetarian $\dagger$

Vegetarian

Vegetable servings per wk

Fruit servings per wk

Eggs (including yolks) per wk

$\leq 15$ vegetable + fruit + egg

servings per wk

$>15$ vegetable + fruit + egg servings per wk

Oily fish servings per wk

Alcohol units per wk

Regular exercise, $n$

Yes

No

$6(6 \%)$

$3(3 \%)$

$92(91 \%)$

$0.41 \pm 0.13$

$72(71 \%)$

$8(8 \%)$

$21(21 \%)$

$7.0 \pm 5.2(n=100)$

$6.6 \pm 5.8(n=100)$

$1.8 \pm 2.1(n=100)$

$59(59 \%)$

$41(41 \%)$

$0.7 \pm 1.1(n=101)$

$3.8 \pm 8.2(n=101)$

44 (44\%)

$57(56 \%)$

$0.43 \pm 0.13$

$0.44 \pm 0.15$

Time spent outside per wk, $\mathrm{h}$

Autumn/winter

Spring/summer

Autumn/winter daylight exposure $\leq 7 \mathrm{~h}$

Autumn/winter daylight exposure $>7 \mathrm{~h}$

Spring/summer daylight exposure $\leq 15 \mathrm{~h}$

Spring/summer daylight

exposure $>15 \mathrm{~h}$

$8.7 \pm 5.8(n=100) \quad$ N/A

$17.0 \pm 10.0(n=100) \quad$ N/A

$56(56 \%) \quad 0.43 \pm 0.14$

$44(44 \%) \quad 0.44 \pm 0.15$

$52(52 \%) \quad 0.43 \pm 0.13$

$48(48 \%) \quad 0.44 \pm 0.15$

Regular strong sunlight exposure, $n$

$\begin{array}{lll}\text { Yes } & 24(24 \%) & 0.43 \pm 0.13 \\ \text { No } & 77(76 \%) & 0.44 \pm 0.15\end{array}$

Table 1. Continued

\begin{tabular}{lcc}
\hline \multicolumn{1}{c}{ Variable } & Value & MPOD \\
\hline $\begin{array}{l}\text { Sunbed use, } n \\
\quad \text { Yes }\end{array}$ & $1(1 \%)$ & N/A \\
$\quad$ No & $100(99 \%)$ & N/A \\
Skin sensitivity to sunlight, $n$ & & \\
$\quad$ Yes & $12(12 \%)$ & $0.46 \pm 0.11$ \\
$\quad$ No & $89(88 \%)$ & $0.43 \pm 0.14$ \\
Sunglasses use in bright conditions, $n$ & & \\
$\quad$ Always/most of the time & $19(19 \%)$ & $0.40 \pm 0.16$ \\
$\quad \begin{array}{l}\text { Sometimes/occasionally } \\
\text { Very rarely/never }\end{array}$ & $39(39 \%)$ & $0.43 \pm 0.13$ \\
Spectacle prescription & $43(43 \%)$ & $0.45 \pm 0.14$ \\
$\quad-$ best vision sphere, DS & $-2.08 \pm 2.82(n=110)$ & N/A \\
Refractive correction, $n$ & & \\
$\quad$ Spectacles and/or UV-blocking & & \\
$\quad$ contact lenses & $39(37 \%)$ & $0.47 \pm 0.15$ \\
$\quad$ None or non-UV-blocking & & \\
$\quad$ contact lenses & $62(59 \%)$ & $0.42 \pm 0.14$ \\
Mixture & $4(4 \%)$ & N/A \\
Family history of AMD, $n$ & & \\
Yes & $2(2 \%)$ & N/A \\
No & $99(98 \%)$ & N/A \\
\hline
\end{tabular}

Note: Information on vitamin and supplement use was also acquired from the questionnaire, but it is not included here as very few subjects took either, and of those that did, no vitamins/ supplements included lutein or zeaxanthin. N/A, not applicable.

${ }^{*} P<0.01$ (i.e., male MPOD significantly higher than female MPOD).

† Part vegetarian refers to someone who eats one form of meat only (e.g., fish)

grounds other than Indian and Pakistani, smoking status, sunbed use, and family history of AMD. For the same reason, some variables were modified: iris colors other than dark brown were combined to make a larger group that could then be compared with dark brown; part vegetarians were excluded from the dietary background analysis; and the 'mixture' group was excluded from the refractive correction analysis.

Of the variables examined, only sex demonstrated a statistically significant difference in MPOD, with the males having a higher average MPOD than the females $(P=0.008)$. Figure 1 shows the frequency distribution of MPOD for both groups.

Aside from sex, another variable that approached significance $(P=0.059)$ was refractive correction; individuals who wore spectacles (which absorb some or all UV light) or UVfiltering contact lenses (CLs) full time had a higher mean MPOD than those who wore no spectacles or non-UV-filtering CLs (Table 1). There was also a possible trend for iris color; subjects with dark brown eyes had a higher mean MPOD than subjects with lighter ("other") eyes $(P=0.078)$. The spread of MPOD in these two groups is shown in Figure 2. Table 2 shows the individual MPOD breakdown of the more unusual iris colors in the non-dark brown category (unusual, that is, for an Asian population), so brown irides, which accounted for the largest percentage eye color in this group, have been omitted. All but one MPOD value was below the overall average of $0.43 \pm 0.14$ and below the "other" iris color group's average of $0.41 \pm 0.13$.

In addition to looking for differences in mean MPOD between the various groups, the possibility of any MPOD associations was explored for the continuous data. Using Pearson's $r$ or Spearman's rho (dependent on normality), and 


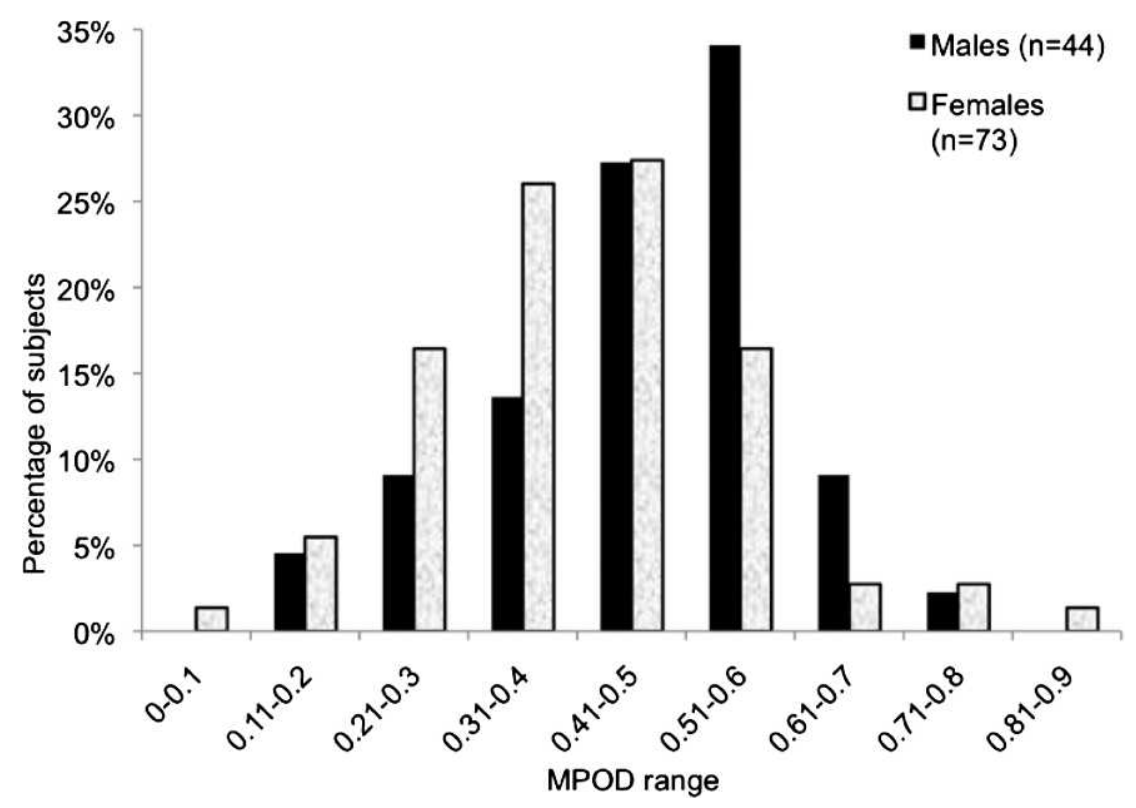

Figure 1. The frequency distribution of MPOD for males and females in the Asian group.

scatter graph observations, virtually no significant correlations between MPOD and any variable (age, BMI, vegetable intake, fruit intake, vegetables/fruits combined, egg intake, vegetables/ fruits/eggs combined, oily fish intake, alcohol intake, hours spent outside, and best vision sphere) were found, even when analyzing males and females separately (in view of the MPOD sex difference). The only significant correlation to emerge was a positive association between MPOD and alcohol intake (rho $=$ $0.229, P=0.021$ ). This association remained significant for females (rho $=0.330, P=0.009$ ), but not for males (rho $=$ $0.108, P=0.511$ ). However, observation of the scatter graphs indicated that the large proportion of subjects who did not drink alcohol (61\%) might have influenced the correlations. Indeed, separating the group as a whole into drinkers of alcohol and nondrinkers resulted in no relationship for alcohol units and MPOD (rho $=0.045, P=0.782$ ).

\section{Asian Versus White MPOD Comparisons}

Data from one white subject was removed from the analyses due to inability to complete the MPS test. The total number of Whites was 52 ( 15 males, 37 females), and their mean MPOD was $0.33 \pm 0.13$, compared with $0.43 \pm 0.14$ for the 117 Asian subjects. These means are significantly different $(P<0.0005)$, as demonstrated in Table 3. Figure 3 is a frequency distribution of MPOD for each group. The white group was older than the Asian group, on average, and a significant decline in MPOD with age was present in this particular sample (Fig. 4), which could therefore be the cause of the differing MPOD means

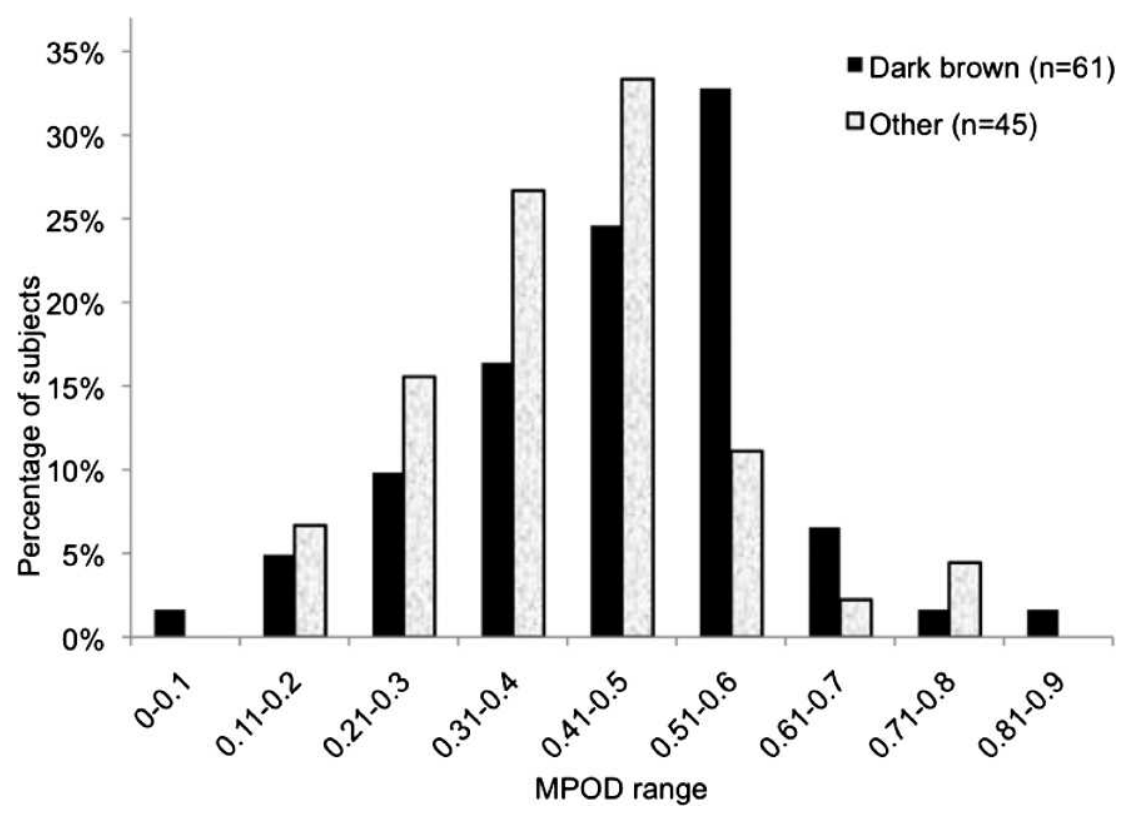

Figure 2. The frequency distribution of MPOD for individuals with dark brown eyes and other colored eyes (brown, light brown, hazel, green) in the Asian group. 
TABLE 2. The Individual MPOD Values of the Eight Asian Subjects With Iris Colors Other Than Dark Brown or Brown

\begin{tabular}{lcl}
\hline Iris Color & MPOD & Sex \\
\hline Light brown & 0.36 & Male \\
Hazel & 0.58 & Male \\
Hazel & 0.26 & Female \\
Hazel & 0.30 & Female \\
Hazel & 0.35 & Female \\
Hazel & 0.38 & Female \\
Green & 0.31 & Female \\
Green & 0.36 & Female \\
\hline
\end{tabular}

between the two races. Although there was still a difference in the mean ages $(P=0.01)$, limiting the white subjects to the same age range as the Asian subjects (18-30 years, $n=39$ Whites) removed the MPOD age correlation ( $r h o=-0.135, P=$ 0.413 ), but a statistically significant difference between the two MPOD means $(P=0.002)$ was maintained. Finally, MPOD in the white group was examined for any sex differences. In contrast to the Asians, the mean MPOD in males $(0.30 \pm 0.14)$ was lower than the mean MPOD in females $(0.34 \pm 0.13)$, but this difference was not statistically significant $(P=0.385)$.

\section{Discussion}

The present investigation aimed to determine the range of MPOD in a healthy group of young adults of South Asian origin, to investigate whether any dietary factors or personal characteristics were related to intersubject variations in MPOD, and to compare the mean MPOD of a South Asian group with that of a white group.

The mean MPOD of the Asian subjects was higher than most previously published MPS-based averages, ${ }^{54,59-64}$ the exceptions being the MPOD means reported by Qin et al. ${ }^{65}$ and Tsika et al. ${ }^{66}(0.47$ and 0.52 , respectively). While not being directly comparable (because of the different HFP instruments used), Raman et al. also reported a high MPOD mean of $0.50 \pm$ 0.21 at $0.5^{\circ}$ in their group of South Asian subjects. ${ }^{53}$ It therefore seems very likely that South Asians have higher MP levels, on average, than other, predominantly white, subjects, although we recognize that none of our particular population sample were born in Asia, and so may not be representative of South Asians in general. However, it is still useful to know if people of South Asian origin living in developed countries have higher MPOD, as they may have less chance of AMD, which is important in terms of AMD screening in developed countries, and also in terms of planning public health expenditure.

We found Asian males averaged a statistically significant higher mean MPOD than females. This finding is in common with several other studies, ${ }^{34,43,56,61,67-72}$ while the converse has been rarely reported. ${ }^{58}$ Nevertheless, the majority of studies have not found any sex differences, and in the present study the effect size $(r=0.25)$ was only small to medium. Of

Table 3. MPOD Comparisons Between the Asian and White Groups

\begin{tabular}{lll}
\hline \multicolumn{1}{c}{ Variable } & \multicolumn{1}{c}{ Asian Group } & White Group \\
\hline MPOD & $0.43 \pm 0.14(n=117)$ & $0.33 \pm 0.13(n=52)^{*}$ \\
Age, y & $21.3 \pm 2.6(n=117)$ & $27.6 \pm 9.3(n=52)^{*}$ \\
Age, 18 to $30 \mathrm{y}$ & $21.3 \pm 2.6(n=117)$ & $23.2 \pm 3.6(n=39) \dagger$ \\
MPOD, 18 to $30 \mathrm{y}$ & $0.43 \pm 0.14(n=117)$ & $0.35 \pm 0.14(n=39) \ddagger$ \\
\hline & & \\
& $* P<0.0005$. & \\
$\dagger P<0.01$. & & \\
$\ddagger P<0.005$. &
\end{tabular}

note, Raman et al., in their MPOD study of South Asians, reported higher MPOD in males $(0.54 \pm 0.14, n=30)$ than females $(0.47 \pm 0.18, n=30)$ in their participant age group (20-29) similar to the present study, but this difference was not statistically significant $(P=0.087) .53$

Aside from the male/female difference, MPOD in the present study was unrelated to virtually all the physical, ocular, lifestyle, dietary, and environmental factors determined from the questionnaire. In some cases this could, in part, be the result of too small a sample size, such as the limited number of vegetarians compared with meat eaters. It may also be due to problems inherent in our data collection methods, such as relying on self-reported height and weight to calculate BMI.

There was an almost significant MPOD difference between individuals who wore spectacles or UV-filtering CLs full time and those who wore no spectacles or non-UV-filtering CLs. These differences were not attributable to greater numbers of males in the spectacle/UV CL group (36\% males/64\% females) compared with the no spectacles/non-UV CL group ( $42 \%$ males $/ 58 \%$ females). We previously reported significantly greater MPOD $(P=0.014)$ in eyes that had worn UV-blocking CLs $(0.41 \pm 0.13)$ compared with eyes that had worn non-UVblocking CLs $(0.33 \pm 0.15)$ for the previous 5 years. ${ }^{97}$ Light exposure, particularly UV and blue light, is damaging to the retina, ${ }^{73-76}$ and it has been shown to cause the production of free radicals, leading to oxidative stress and possibly AMD. ${ }^{39}$ From population-based studies, there is some evidence to suggest that chronic light exposure is a risk factor for AMD. ${ }^{77-79}$ With less UV light reaching the retina as a result of absorption by spectacles or UV CLs, there may be less lightinduced oxidative stress in the retina, thus, permitting an augmentation of MP by reducing its antioxidant-function workload. Interestingly, there was no MPOD relationship with questionnaire-reported sunglasses use or light exposure. This could be because sunglasses are mostly worn in bright conditions (and the questionnaire only asked about their use in bright conditions), so the UV protection is intermittent. Spectacles and CLs would be worn more often, out of necessity to see clearly (and the questionnaire asked specifically about the frequency of spectacle/CL wear and their use in public), so chronic exposure to UV light would be less than with sunglasses. Furthermore, it has been documented that high MPODs are associated with better glare resistance. ${ }^{80-83}$ As a result, those with higher MPOD may feel less inclined to wear sunglasses. Although not reaching statistical significance, this could explain the higher MPOD means in those subjects reporting very little sunglasses use compared with those reporting frequent use (Table 1). For light exposure, the questions on time spent outdoors were far and above the ones that participants struggled with the most, so the lack of any significant correlation may in part be a reflection of the overall difficulties in establishing an individual's light exposure.

A comparison between Asians and Whites was not the main focus of this study, and, therefore, the data interpretation is limited in this respect. It is interesting, nonetheless, that in comparing the Asian MPOD mean with the white MPOD mean, highly significant differences were revealed (Asian MPOD higher than white MPOD), regardless of age restrictions (Table 3 ). Even though there was still some MP overlap between the two groups (Fig. 3), and a lot of variation left unexplained (the effect size, $r$, was 0.35 , i.e., a medium effect), the difference was clear. The low fruit and vegetable consumption of the Asian group suggests that this difference is unlikely to be the result of dietary factors, although without such data available for the white subjects, this clearly cannot be confirmed. It also seems unlikely that sex differences between the groups would be a factor, because the ratio of males to females in each group 


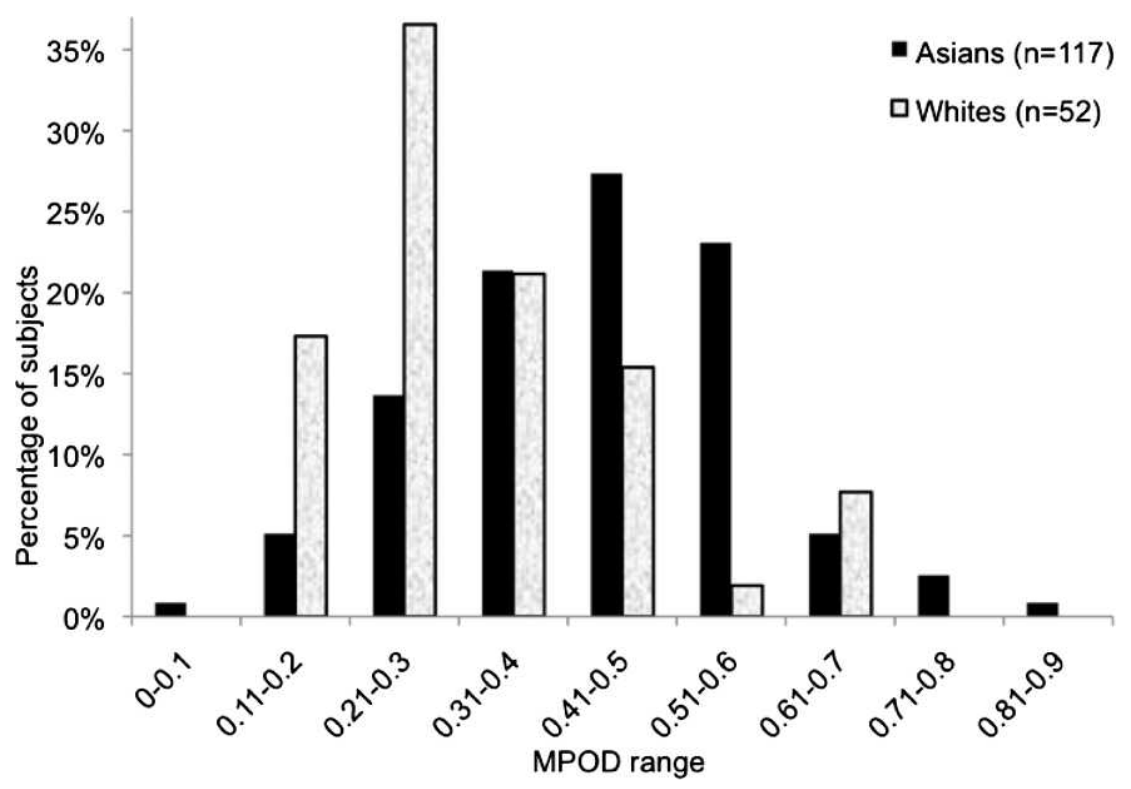

Figure 3. The frequency distribution of MPOD in the Asian and white subjects.

was similar, and comparison tests demonstrated significant MPOD differences even when each sex was considered separately ( $P<0.0005$ for males, $P<0.005$ for females). It, therefore, seems reasonable to assume that the cause lies elsewhere.

Firstly, various aspects of foveal architecture have been associated with MPOD. For instance, Nolan et al. ${ }^{46}$ found MPOD to be positively and significantly correlated with foveal width $(r=0.41, P=0.001)$, and moreover, that the foveas of non-Whites (Indian/Asian/Hispanic/black) were significantly wider than the foveas of Whites $(P<0.05)$. Consequently, it is possible that ethnic variations in foveal architecture could be a reason for the disparity in MPOD, at least in part. From this point of view, it would have been useful to know the spatial profile of MP for the study participants, but we could not measure this with the MPS.

Secondly, iris color, or more specifically melanin, could account for the differences in MPOD between the two groups. Like MP, melanin absorbs short-wavelength light (mainly UV)

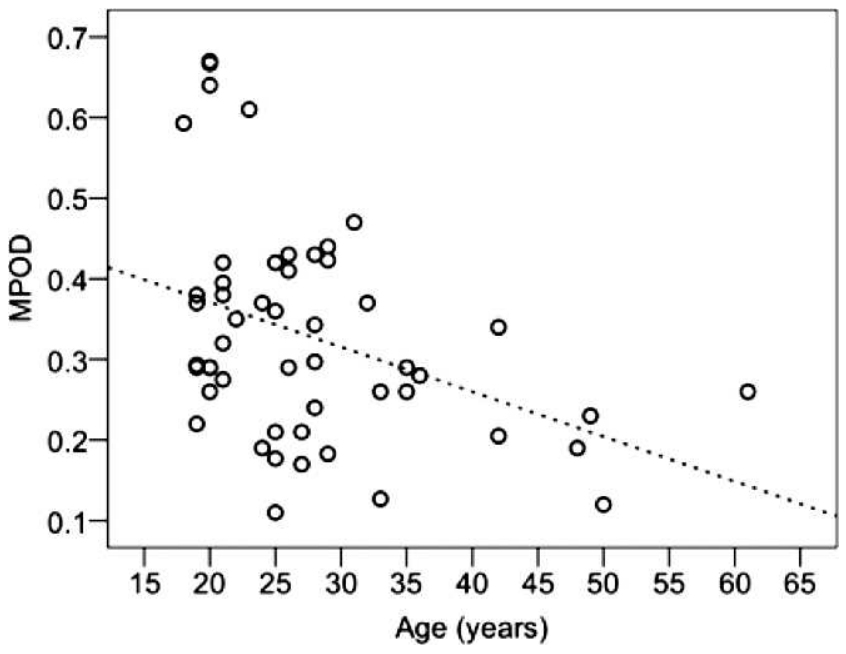

Figure 4. The relationship between age and MPOD for the white subjects (Spearman's rho $=-0.357, P=0.009$ ). and has antioxidant properties. In the iris its function is predominantly the former, and in the retinal pigment epithelium and choroid its function is predominantly the latter. $^{84}$ Light irides, which contain less melanin than dark irides, have been identified as a risk factor for AMD, ${ }^{4,85-89}$ and a risk factor for low MP, ${ }^{34,47,56,68,83,90-92}$ so in an ethnic group where the majority of irides are dark, it seems logical that they might have higher levels of MP (and a lower risk for AMD) than an ethnic group with a mixture of light and dark iris colors. On account of the expected high propensity of dark irides in the Asian subjects, an eye color related MPOD difference within this group was not anticipated, but it was split into a "dark brown" and an "other" category, and although not reaching statistical significance, there did appear to be a trend towards the darker brown eyes having higher MPOD. Iris color in this study, as in others, ${ }^{34,56,90}$ was selfreported and not verified, so the fact that a difference may exist between two such subtle iris color groups lends support to the theory of melanin being involved with MPOD differences between racial groups. In order to rule out the possibility of a greater male dominance in the dark brown than the "other" iris group (with subsequent higher MPOD being the result of sex rather than eye color), the means were compared separately. For males, the difference became more insignificant, dark brown mean $(n=24)$ : $0.47 \pm 0.12$, "other" mean $(n=16): 0.48 \pm 0.13(P=0.707)$. For females, however, the difference became statistically significant, dark brown mean $(n=37): 0.45 \pm 0.16$, "other" mean $(n=29): 0.37 \pm$ $0.12(P=0.021)$. After exploring this further, by examining the individual MPODs of those subjects with more unusual iris colors, it was striking that all but one MPOD value was well below the overall Asian MPOD average and below the "other" iris color group's MPOD average. It, therefore, seems highly plausible that iris color is a cause of the racial differences in mean MPOD observed in this study. By filtering out more light than lighter colored eyes, dark eyes could reduce the amount of harmful wavelengths reaching the retina, ${ }^{47,84}$ and as a result, there might be a lowering of oxidative stress and less depletion of MP than in lighter eyes. Another possibility, as suggested by Hammond et al., ${ }^{47}$ is that melanin and MP deposition are co-inherited traits. 
A final rationale for racial differences in MPOD could lie in ethnicity-variant genetics besides melanin, but the possibilities in this respect are highly diverse. For example, there might be ethnic variations in how effectively $\mathrm{L}$ and $\mathrm{Z}$ are absorbed, transported or deposited, or there could be specific genes/ alleles that lead to higher or lower MPOD, or indeed the first example could be the result of the second. Twin studies on MPOD have demonstrated that there is definitely a genetic component involved, ${ }^{93,94}$ and a spousal-based MPOD study appeared to confirm this also; despite statistically significant correlations for dietary and blood serum levels of $\mathrm{L}$ and $\mathrm{Z}$ between married couples, MPOD between husbands and wives was not correlated at all. ${ }^{95}$ Recently a specific gene and its respective genotypes were examined as part of an MPOD study; Loane et al. ${ }^{96}$ compared MPOD in three different genotype groups of the apolipoprotein $\mathrm{E}$ gene, a gene that codes for lipoproteins that may carry $\mathrm{L}$ and $\mathrm{Z}$ in serum. It was found that subjects in one of the genotype groups, which contained at least one specific allele, had significantly higher MPOD than subjects in the other two groups, which were both without the specific allele. (As described by Loane et al., the allele in question, Apo $\varepsilon 4$, has also been shown to reduce the risk for AMD). This confirms again the genetic aspect of MP, which is not unexpected given the still large amount of unexplained intersubject MPOD variation in the current study and many previous ones.

In conclusion, MPOD in this group of young adults of South Asian origin was largely unrelated to any physical, ocular, lifestyle, dietary, or environmental factors. Males and females, however, did have significantly different MPOD levels, and compared with a group of Whites, MPOD was significantly higher in the Asians, which in turn could mean a decreased risk for AMD. As demonstrated in the introduction, though, current information on AMD prevalence in South Asians, particularly with respect to comparisons with Whites, is limited. Future research will hopefully address this, and wider scale studies examining and comparing MPOD in different racial groups, including South Asians, would be desirable.

\section{Acknowledgments}

Disclosure: O. Howells, None; F. Eperjesi, None; H. Bartlett, None

\section{References}

1. Sommer A, Tielsch JM, Katz J, et al. Racial differences in the cause-specific prevalence of blindness in east Baltimore. $N$ Engl J Med. 1991;325:1412-1417.

2. Rahmani B, Tielsch JM, Katz J, et al. The cause-specific prevalence of visual impairment in an urban population. The Baltimore Eye Survey. Ophthalmology. 1996;103:1721-1726.

3. Klein R, Clegg L, Cooper LS, et al. Prevalence of age-related maculopathy in the Atherosclerosis Risk in Communities Study. Arch Ophthalmol. 1999;117:1203-1210.

4. Frank RN, Puklin JE, Stock C, Canter LA. Race, iris color, and age-related macular degeneration. Trans Am Ophthalmol Soc. 2000;98:109-117.

5. Muñoz B, West SK, Rubin GS, et al. Causes of blindness and visual impairment in a population of older Americans: the Salisbury Eye Evaluation Study. Arch Ophthalmol. 2000;118: 819-825.

6. Klein R, Klein BE, Marino EK, et al. Early age-related maculopathy in the cardiovascular health study. Ophthalmology. 2003;110:25-33.

7. Congdon N, O'Colmain B, Klaver CC, et al. Causes and prevalence of visual impairment among adults in the United States. Arch Ophthalmol. 2004;122:477-485.
8. Friedman DS, O'Colmain BJ, Muñoz B, et al. Prevalence of agerelated macular degeneration in the United States. Arch Ophthalmol. 2004;122:564-572.

9. Friedman DS, West SK, Munoz B, et al. Racial variations in causes of vision loss in nursing homes: the Salisbury Eye Evaluation in Nursing Home Groups (SEEING) Study. Arch Ophthalmol. 2004;122:1019-1024.

10. Leske MC, Wu SY, Hennis A, et al. Nine-year incidence of agerelated macular degeneration in the Barbados Eye Studies. Ophthalmology. 2006;113:29-35.

11. Duan Y, Mo J, Klein R, et al. Age-related macular degeneration is associated with incident myocardial infarction among elderly Americans. Ophthalmology. 2007;114:732-737.

12. Klein R, Chou CF, Klein BE, Zhang X, Meuer SM, Saaddine JB. Prevalence of age-related macular degeneration in the US population. Arch Ophthalmol. 2011;129:75-80.

13. Vanderbeek BL, Zacks DN, Talwar N, Nan B, Musch DC, Stein JD. Racial differences in age-related macular degeneration rates in the United States: a longitudinal analysis of a managed care network. Am J Ophthalmol. 2011;152:273-282.

14. Chang TS, Hay D, Courtright P. Age-related macular degeneration in Chinese-Canadians. Can J Ophthalmol. 1999;34:266271.

15. Oshima Y, Ishibashi T, Murata T, Tahara Y, Kiyohara Y, Kubota T. Prevalence of age related maculopathy in a representative Japanese population: the Hisayama study. $\mathrm{Br} J$ Ophthalmol. 2001;85:1153-1157.

16. Rodriguez J, Sanchez R, Munoz B, et al. Causes of blindness and visual impairment in a population-based sample of U.S. Hispanics. Ophthalmology. 2002;109:737-743.

17. Iwase A, Araie M, Tomidokoro A, Yamamoto T, Shimizu H, Kitazawa Y. Prevalence and causes of low vision and blindness in a Japanese adult population: the Tajimi Study. Ophthalmology. 2006;113:1354-1362.

18. Li Y, Xu L, Jonas JB, Yang H, Ma Y, Li J. Prevalence of agerelated maculopathy in the adult population in China: the Beijing Eye Study. Am J Ophthalmol. 2006;142:788-793.

19. Sivaprasad S, Membrey WL, Sivagnanavel V, et al. Second eye of patients with unilateral neovascular age-related macular degeneration: Caucasians vs Chinese. Eye (Lond). 2006;20: 923-926.

20. Yasuda M, Kiyohara Y, Hata Y, et al. Nine-year incidence and risk factors for age-related macular degeneration in a defined Japanese population the Hisayama study. Ophthalmology. 2009; 116:2135-2140.

21. Varma R, Foong AW, Lai MY, Choudhury F, Klein R, Azen SP. Four-year incidence and progression of age-related macular degeneration: the Los Angeles Latino Eye Study. Am J Opbthalmol. 2010;149:741-751.

22. Krishnaiah S, Das T, Nirmalan PK, et al. Risk factors for agerelated macular degeneration: findings from the Andhra Pradesh Eye Disease Study in South India. Invest Ophthalmol Vis Sci. 2005;46:4442-4449.

23. Gupta SK, Murthy GV, Morrison N, et al. Prevalence of early and late age-related macular degeneration in a rural population in northern India: the INDEYE feasibility study. Invest Ophthalmol Vis Sci. 2007;48:1007-1011.

24. Krishnaiah S, Das TP, Kovai V, Rao GN. Associated factors for age-related maculopathy in the adult population in southern India: the Andhra Pradesh Eye Disease Study. Br J Ophthalmol. 2009;93:1146-1150.

25. Cheung CMG, Tai ES, Kawasaki R, et al. Prevalence of and risk factors for age-related macular degeneration in a multiethnic Asian cohort. Arch Ophthalmol. 2012;130:480-486.

26. Kawasaki R, Yasuda M, Song SJ, et al. The prevalence of agerelated macular degeneration in Asians: a systematic review and meta-analysis. Ophthalmology. 2010;117:921-927. 
27. Bone RA, Landrum JT, Hime GW, Cains A, Zamor J. Stereochemistry of the human macular carotenoids. Invest Ophthalmol Vis Sci. 1993;34:2033-2040.

28. Malinow MR, Feeney-Burns L, Peterson LH, Klein ML, Neuringer M. Diet-related macular anomalies in monkeys. Invest Ophthalmol Vis Sci. 1980;19:857-863.

29. Neuringer M, Sandstrom MM, Johnson EJ, Snodderly DM. Nutritional manipulation of primate retinas, I: effects of lutein or zeaxanthin supplements on serum and macular pigment in xanthophyll-free rhesus monkeys. Invest Ophthalmol Vis Sci. 2004; 45:3234-3243.

30. Wyszecki G, Stiles WS. The eye. Color Science: Concepts and Methods, Quantitative Data and Formulae. New York: WileyInterscience; 1982:112-114

31. Snodderly DM, Brown PK, Delori FC, Auran JD. The macular pigment. I. Absorbance spectra, localization, and discrimination from other yellow pigments in primate retinas. Invest Ophthalmol Vis Sci. 1984;25:660-673.

32. Handelman GJ, Snodderly DM, Krinsky NI, Russett MD, Adler AJ. Biological control of primate macular pigment - biochemical and densitometric studies. Invest Ophthalmol Vis Sci. 1991;32:257-267.

33. Bone RA, Landrum JT, Cains A. Optical density spectra of the macular pigment in vivo and in vitro. Vision Res. 1992;32: 105-110.

34. Hammond BR, Caruso-Avery M. Macular pigment optical density in a southwestern sample. Invest Ophthalmol Vis Sci. 2000;41:1492-1497.

35. Landrum JT, Bone RA. Lutein, zeaxanthin, and the macular pigment. Arch Biochem Biophys. 2001;385:28-40.

36. Chucair AJ, Rotstein NP, SanGiovanni JP, During A, Chew EY, Politi LE. Lutein and zeaxanthin protect photoreceptors from apoptosis induced by oxidative stress: relation with docosahexaenoic acid. Invest Ophthalmol Vis Sci. 2007;48:51685177.

37. Khachik F, Bernstein PS, Garland DL. Identification of lutein and zeaxanthin oxidation products in human and monkey retinas. Invest Ophthalmol Vis Sci. 1997;38:1802-1811.

38. Beatty S, Koh H-H, Henson D, Boulton M. The role of oxidative stress in the pathogenesis of age-related macular degeneration. Surv Ophthalmol. 2000;45:115-134.

39. Algvere PV, Marshall J, Seregard S. Age-related maculopathy and the impact of blue light hazard. Acta Ophthalmol Scand. 2006;84:4-15.

40. Beatty S, Murray IJ, Henson DB, Carden D, Koh HH, Boulton ME. Macular pigment and risk for age-related macular degeneration in subjects from a Northern European population. Invest Ophthalmol Vis Sci. 2001;42:439-446.

41. Bone RA, Landrum JT, Mayne ST, Gomez CM, Tibor SE, Twaroska EE. Macular pigment in donor eyes with and without AMD: A case-control study. Invest Ophthalmol Vis Sci. 2001;42:235-240.

42. Richer S, Stiles W, Statkute L, et al. Double-masked, placebocontrolled, randomized trial of lutein and antioxidant supplementation in the intervention of atrophic age-related macular degeneration: the Veterans LAST study (Lutein Antioxidant Supplementation Trial). Optometry. 2004;75:216-230.

43. Nolan JM, Stack J, O'Donovan O, Loane E, Beatty S. Risk factors for age-related maculopathy are associated with a relative lack of macular pigment. Exp Eye Res. 2007;84:61-74.

44. Wolf-Schnurrbusch UEK, Roosli N, Weyermann E, Heldner MR, Hohne $\mathrm{K}$, Wolf S. Ethnic differences in macular pigment density and distribution. Invest Ophthalmol Vis Sci. 2007;48: 3783-3787.

45. Iannaccone A, Mura M, Gallaher KT, et al. Macular pigment optical density in the elderly: findings in a large biracial midsouth population sample. Invest Ophthalmol Vis Sci. 2007; 48:1458-1465.
46. Nolan JM, Stringham JM, Beatty S, Snodderly DM. Spatial profile of macular pigment and its relationship to foveal architecture. Invest Ophthalmol Vis Sci. 2008;49:2134-2142.

47. Hammond BR, Fuld K, Snodderly DM. Iris color and macular pigment optical density. Exp Eye Res. 1996;62:715-720.

48. Bernstein PS, Zhao DY, Wintch SW, Ermakov IV, McClane RW, Gellermann W. Resonance Raman measurement of macular carotenoids in normal subjects and in age-related macular degeneration patients. Ophthalmology. 2002;109:1780-1787.

49. Tang CY, Yip HS, Poon MY, Yau WL, Yap MKH. Macular pigment optical density in young Chinese adults. Ophthalmic Physiol Opt. 2004;24:586-593.

50. Lam RF, Rao SK, Fan DSP, Lau FTC, Lam DSC. Macular pigment optical density in a Chinese sample. Curr Eye Res. 2005;30: 729-735.

51. Obana A, Hiramitsu T, Gohto Y, et al. Macular carotenoid levels of normal subjects and age-related maculopathy patients in a Japanese population. Ophthalmology. 2008;115:147-157.

52. Sasamoto Y, Gomi F, Sawa M, Sakaguchi H, Tsujikawa M, Hamasaki T. Macular pigment optical density in central serous chorioretinopathy. Invest Opbthalmol Vis Sci. 2010;51:52195225.

53. Raman R, Rajan R, Biswas S, Vaitheeswaran K, Sharma T. Macular pigment optical density in a South Indian population. Invest Ophthalmol Vis Sci. 2011;52:7910-7916.

54. van der Veen RLP, Berendschot TTJM, Hendrikse F, Carden D, Makridaki M, Murray IJ. A new desktop instrument for measuring macular pigment optical density based on a novel technique for setting flicker thresholds. Ophthalmic Physiol Opt. 2009;29:127-137.

55. Howells O, Eperjesi F, Bartlett H. Improving the repeatability of heterochromatic flicker photometry for measurement of macular pigment optical density. Graefes Arch Clin Exp Ophthalmol. 2013;251:871-880.

56. Mellerio J, Ahmadi-Lari S, van Kuijk F, Pauleikhoff D, Bird A, Marshall J. A portable instrument for measuring macular pigment with central fixation. Curr Eye Res. 2002;25:37-47.

57. Burke JD, Curran-Celentano J, Wenzel AJ. Diet and serum carotenoid concentrations affect macular pigment optical density in adults 45 years and older. $J$ Nutr. 2005;135:12081214.

58. Nolan JM, Kenny R, O'Regan C, et al. Macular pigment optical density in an ageing Irish population: The Irish Longitudinal Study on Ageing. Opbthalmic Res. 2010;44:131-139.

59. Makridaki M, Carden D, Murray IJ. Macular pigment measurement in clinics: controlling the effect of the ageing media. Ophthalmic Physiol Opt. 2009;29:338-344.

60. van der Veen RLP, Berendschot TTJM, Makridaki M, Hendrikse F, Carden D, Murray IJ. Correspondence between retinal reflectometry and a flicker-based technique in the measurement of macular pigment spatial profiles. J Biomed Opt. 2009; 14:064046.

61. Bartlett H, Stainer L, Singh S, Eperjesi F, Howells O. Clinical evaluation of the MPS 9000 Macular Pigment Screener. $\mathrm{Br} \mathrm{J}$ Ophthalmol. 2010;94:753-756.

62. Berrow EJ, Bartlett HE, Eperjesi F. Do lutein, zeaxanthin and macular pigment optical density differ with age or age-related maculopathy? e-SPEN. 2011;6:e197-e201.

63. de Kinkelder R, van der Veen RLP, Verbaak FD, Faber DJ, van Leeuwen TG, Berendschot TTJM. Macular pigment optical density measurements: evaluation of a device using heterochromatic flicker photometry. Eye (Lond). 2011;25:105-112.

64. Richer, SP, Stiles W, Graham-Hoffman K, et al. Randomized, double-blind, placebo-controlled study of zeaxanthin and visual function in patients with atrophic age-related macular degeneration. The Zeaxanthin and Visual Function Study (ZVF) FDA IND \#78, 973. Optometry. 2011;82:667-680. 
65. Qin L, Bartlett H, Griffiths HR, Eperjesi F, Armstrong RA, Gherghel D. Macular pigment optical density is related to blood glutathione levels in healthy individuals. Invest Ophthalmol Vis Sci. 2011;52:5029-5033.

66. Tsika C, Tsilimbaris MK, Makridaki M, Kontadakis G, Plainis S, Moschandreas J. Assessment of macular pigment optical density (MPOD) in patients with unilateral wet age-related macular degeneration (AMD). Acta Ophthalmol. 2011;89: e573-e578.

67. Hammond BR, Curran-Celentano J, Judd S, et al. Sex differences in macular pigment optical density: relation to plasma carotenoid concentrations and dietary patterns. Vision Res. 1996;36:2001-2012.

68. Wooten BR, Hammond BR, Land RI, Snodderly DM. A practical method for measuring macular pigment optical density. Invest Ophthalmol Vis Sci. 1999;40:2481-2489.

69. Berendschot TTJM, Broekmans WMR, Klöpping-Ketelaars IAA, Kardinaal AFM, van Poppel G, van Norren D. Lens aging in relation to nutritional determinants and possible risk factors for age-related cataract. Arch Ophthalmol. 2002;120:17321737.

70. Broekmans WMR, Berendschot TTJM, Klöpping-Ketelaars IAA, et al. Macular pigment density in relation to serum and adipose tissue concentrations of lutein and serum concentrations of zeaxanthin. Am J Clin Nutr. 2002;76:595-603.

71. Lam RF, Rao SK, Fan DSP, Lau FTC, Lam DSC. Macular pigment optical density in a Chinese sample. Curr Eye Res. 2005;30: 729-735.

72. Yu J, Johnson EJ, Shang F, et al. Measurement of macular pigment optical density in a healthy Chinese population sample. Invest Ophthalmol Vis Sci. 2012;53:2106-2111.

73. Ham WT, Mueller HA, Sliney DH. Retinal sensitivity to damage from short wavelength light. Nature. 1976;260:153-155.

74. Ham WT, Ruffolo JJ, Mueller HA, Clarke AM, Moon ME. Histologic analysis of photochemical lesions produced in rhesus retina by short-wave-length light. Invest Ophthalmol Vis Sci. 1978;17:1029-1035.

75. Ham WT, Ruffolo JJ, Mueller HA, Guerry D. The nature of retinal radiation damage: dependence on wavelength, power level and exposure time. Vision Res. 1980;20:1105-1011.

76. Ham WT, Mueller HA, Ruffolo JJ, Guerry D, Guerry RK. Action spectrum for retinal injury from near-ultraviolet radiation in the aphakic monkey. Am J Ophthalmol. 1982;93:299-306.

77. Taylor HR, West S, Muñoz B, Rosenthal FS, Bressler SB, Bressler NM. The long-term effects of visible light on the eye. Arch Opbthalmol. 1992;110:99-104.

78. Tomany SC, Cruickshanks KJ, Klein R, Klein BEK, Knudtson MD. Sunlight and the 10-year incidence of age-related maculopathy - The Beaver Dam Eye Study. Arch Ophthalmol. 2004; 122:750-757.

79. Hirakawa M, Tanaka M, Tanaka Y, et al. Age-related maculopathy and sunlight exposure evaluated by objective measurement. Br J Ophthalmol. 2008;92:630-634.

80. Wenzel AJ, Fuld K, Stringham JM, Curran-Celentano J. Macular pigment optical density and photophobia light threshold. Vision Res. 2006;46:4615-4622.
81. Stringham JM, Hammond BR. The glare hypothesis of macular pigment function. Optom Vis Sci. 2007;84:859-864.

82. Stringham JM, Hammond BR. Macular pigment and visual performance under glare conditions. Optom Vis Sci. 2008;85: 82-88.

83. Stringham JM, Garcia PV, Smith PA, McLin LN, Foutch BK. Macular pigment and visual performance in glare: benefits for photostress recovery, disability glare, and visual discomfort. Invest Ophthalmol Vis Sci. 2011;52:7406-7415.

84. Hu DN, Simon JD, Sarna T. Role of ocular melanin in ophthalmic physiology and pathology. Photochem Photobiol. 2008;84:639-644.

85. Hyman LG, Lilienfeld AM, Ferris FL, Fine SL. Senile macular degeneration: a case-control study. Am J Epidemiol. 1983;118: 213-227.

86. Weiter JJ, Delori FC, Wing GL, Fitch KA. Relationship of senile macular degeneration to ocular pigmentation. Am J Ophthalmol. 1985;99:185-187.

87. Sandberg MA, Gaudio AR, Miller S, Weiner A. Iris pigmentation and extent of disease in patients with neovascular age-related macular degeneration. Invest Ophthalmol Vis Sci. 1994;35: 2734-2740.

88. Mitchell P, Smith W, Wang JJ. Iris color, skin sun sensitivity, and age-related maculopathy. The Blue Mountains Eye Study. Ophthalmology. 1998;105:1359-1363.

89. Nicolas CM, Robman LD, Tikellis G, et al. Iris colour, ethnic origin and progression of age-related macular degeneration. Clin Experiment Ophthalmol. 2003;31:465-469.

90. Ciulla TA, Curran-Celantano J, Cooper DA, et al. Macular pigment optical density in a midwestern sample. Ophthalmology. 2001;108:730-737.

91. Kirby ML, Beatty S, Loane E, et al. A central dip in the macular pigment spatial profile is associated with age and smoking. Invest Ophthalmol Vis Sci. 2010;51:6722-6728.

92. Sandberg MA, Johnson EJ, Berson EL. The relationship of macular pigment optical density to serum lutein in retinitis pigmentosa. Invest Ophthalmol Vis Sci. 2010;51:1086-1091.

93. Hammond BR, Fuld K, Curran-Celentano J. Macular pigment density in monozygotic twins. Invest Ophthalmol Vis Sci. 1995;36:2531-2541.

94. Liew SHM, Gilbert CE, Spector TD, et al. Heritability of macular pigment: a twin study. Invest Ophthalmol Vis Sci. 2005;46:4430-4436.

95. Wenzel AJ, Sheehan JP, Burke JD, Lefsrud MG, CurranCelentano J. Dietary intake and serum concentrations of lutein and zeaxanthin, but not macular pigment optical density, are related in spouses. Nutr Res. 2007;27:462-469.

96. Loane E, McKay GJ, Nolan JM, Beatty S. Apolipoprotein E genotype is associated with macular pigment optical density. Invest Ophthalmol Vis Sci. 2010;51:2636-2643.

97. Wolffsohn J, Eperjesi F, Bartlett H, et al. Does blocking ultraviolet light with contact lenses benefit eye health? Paper presented at: British Contact Lens Association (BCLA) Conference; May 24-27, 2012; Birmingham, UK. 